\title{
Comparative study on fruit development and oil synthesis in two cultivars of Camellia oleifera
}

Fanhang Zhang ${ }^{1,2}$, Ze Li $i^{1,3^{*}}$, Junqin Zhou ${ }^{1,3}$, Yiyang $\mathrm{Gu}^{1,3}$ and Xiaofeng Tan ${ }^{1,3^{*}}$

\begin{abstract}
Background: The oil-tea tree (Camellia oleifera Abel.) is a woody tree species that produces edible oil in the seed. C. oleifera oil has high nutritional value and is also an important raw material for medicine and cosmetics. In China, due to the uncertainty on maturity period and oil synthesis mechanism of many C. oleifera cultivars, growers may harvest fruits prematurely, which could not maximize fruit and oil yields. In this study, our objective was to explore the mechanism and differences of oil synthesis between two Camellia oleifera cultivars for a precise definition of the fruit ripening period and the selection of appropriate cultivars.

Results: The results showed that 'Huashuo' had smaller fruits and seeds, lower dry seed weight and lower expression levels of fatty acid biosynthesis genes in July. We could not detect the presence of oil and oil bodies in 'Huashuo' seeds until August, and oil and oil bodies were detected in 'Huajin' seeds in July. Moreover, 'Huashuo' seeds were not completely blackened in October with up to $60.38 \%$ of water and approximately $37.98 \%$ of oil in seed kernels whose oil content was much lower than normal mature seed kernels. The oil bodies in seed endosperm cells of 'Huajin' were always higher than those of'Huashuo' from July to October.
\end{abstract}

Conclusion: Our results confirmed that C. oleifera'Huashuo' fruits matured at a lower rate compared to 'Huajin' fruits and that 'Huajin' seeds entered the oil synthesis period earlier than 'Huashuo' seeds. Moreover, 'Huashuo' fruits did not mature during the Frost's Descent period (October 23-24 each year).

Keywords: Camellia oleifera Abel, Fatty acid, Fruit development, Nutrient content, Oil body observation, Transcriptome

\section{Background}

The oil-tea tree (Camellia oleifera Abel.) is an evergreen shrub of Camellia in Theaceae [1-3]. This species is widely distributed in the hilly areas of southern China, and it is one of the four major woody oil plants in the world, along with the olive tree (Olea europaea), oil palm (Elaeis guineensis), and coconut palm (Cocos nucifera)

\footnotetext{
*Correspondence: lize1853@163.com; tanxiaofengcn@126.com ${ }^{1}$ Key Laboratory of Cultivation and Protection for Non-Wood Forest Trees, Ministry of Education, Central South University of Forestry and Technology, Changsha 410004, Hunan, China

Full list of author information is available at the end of the article
}

$[4,5]$. The tea oil extracted from C. oleifera seeds is an edible oil called 'eastern olive oil' which has high nutritional value and health care functions [6, 7]. The unsaturated fatty acid content of tea oil is as high as $90 \%$ with oleic acid content more than $80 \%$, and the oil is rich in squalene, vitamin E, sterols, polyphenols and many other ingredients with health-promoting effects [8-10]. Tea oil is widely used in the pharmaceutical and cosmetics industries. It not only protects the human cardiovascular system and stomach, but also provides an important raw material for some high-end cosmetics [11-13].

From 1978 to 2009, our C. oleifera research team conducted a comparative regional assessment of $84 \mathrm{C}$. 
oleifera clones and selected two cultivars with the most favorable traits (big fruit, high yield, high seed oil content, etc.), which were named the 'Huashuo' and 'Huajin' cultivars by the Forest Variety Committee of the State Forestry Administration [4]. Both cultivars are characterized by large fruits, high and stable yields and strong resistance (average fruit size of C. oleifera is $18.1 \mathrm{~g}$ in China) $[14,15]$. Owing to their high yields, high photosynthetic efficiency and ability to produce strong economic returns, 'Huashuo' and 'Huajin' are widely cultivated in red soil hilly regions in China. In a previous study, researchers found that fruit ripening in these two C. oleifera cultivars occurs during the Frost's Descent period (October 23-24 of each year) [14-16]. However, it has been proven that the oil yield of 'Huashuo' fruit picked in this period is significantly lower than that of other cultivars, which is consistent with the results of laboratory [17]. The reason for this discrepancy may be that the maturity of 'Huashuo' fruits is not the Frost's Descent period (October 23-24 each year).

Fruits are plant storage organs, and in C. oleifera, most nutrients are concentrated in the seeds. Seed development is accompanied by the accumulation of dry weight and decreases in water content. Contreras et al. [18] showed that the peak dry weight of seeds is a manifestation of physiological maturity, and that the dehydration stage is necessary for seeds to develop from young to fully mature [19]. In C. oleifera, the dehydration stage results in a sharp decrease in the water content of fresh seeds from approximately 90 to $40 \%$ [20]. Moreover, the accumulation of lipids is closely related to the increase in dry weight in oil crops [21, 22]. Lipids consist mainly of triacylglycerol in seeds, as well as fatty acids and glycerin [23]. In addition, soluble sugar and starch, which are also used as storage materials, are generally higher in content at the early stages of seed development; as the seed matures, their contents gradually decrease $[24,25]$. Furthermore, the triacylglycerol molecules in seed endosperm cells could disperse to form oil bodies or liposomes [26, 27]. In previous studies, researchers concluded that the oil body size and area in cells are positively correlated with the seed oil content [28-30]. Therefore, it is crucial to study the development of $C$. oleifera fruits in relation to their external morphology, internal nutrients, and oil body distribution.

Genes play a deterministic role in terms of phenotype, and transcriptome sequencing can provide great insight into the function of C. oleifera genes [31-33]. In recent years, $C$. oleifera researchers have generated a large quantity of data using transcriptome sequencing. By using C. oleifera 'Huashuo' as the test material and analyzing transcriptome data, Jiang et al. [34] found that PLA2, FAD2 and FAD3 could regulate the synthesis of $\alpha$-linolenic acid in C. oleifera seeds, Zeng et al. [35] found that the mRNA levels of $\operatorname{CoFBA}$ and $\operatorname{CoSAD}$ were closely related to the oil content in oil-tea tree seeds. Gong et al. [36] explored the oil biosynthesis and accumulation of $C$. oleifera seeds at five different developmental stages. Moreover, Peng et al. [37] and Lin et al. [38] used RNA-seq technology to study seeds development and lipid synthesis in different $C$. oleifera cultivars, which provide a new insight into the lipid biosynthesis and fatty acid accumulation mechanism. Wu et al. [39] conducted a comparative transcriptome study on highoil and low-oil C. oleifera cultivars and found that the high expression of SAD accelerated oleic acid synthesis and accumulation and the low expression of FAD and FAE1 decreased the consumption of oleic acid for conversion. However, there are few comparative studies about seed development and lipid synthesis among different cultivars of $C$. oleifera. Therefore, RNA-seq technology may help elucidate the developmental differences in oil-tea tree seeds among different cultivars.

In this study, we carried a comparative study on the changes in phenotype, nutrient composition, fatty acids and oil bodies during fruit development in 'Huashuo' and 'Huajin' of Camellia oleifera. RNA sequencing was performed on the seeds of the two cultivars to explore differentially expressed genes in fatty acid biosynthesis pathways. Our objective was to explore the mechanism and difference of oil synthesis between two C. oleifera cultivars. Meanwhile, determining the differences in fruit development between the two main cultivars will lay a theoretical foundation for a precise definition of the ripening period of the oil-tea tree fruit and the selection of appropriate cultivars.

\section{Results}

\section{Fruit development and shape index}

The tree body of C. oleifera 'Huashuo' is half-open, the leaves are dark green and flat and the fruit is oblate and yellowish brown (Fig. 1A and B). By contrast, C. oleifera 'Huajin' has a compact crown and dark green leaves with a rich luster and the fruit is a capsule with an oval shape and an emerald green fruit color (Fig. 1C and D). The fruits of C. oleifera 'Huajin' were more mature than those of C. oleifera 'Huashuo' at the same developmental stages based on their darker seeds (Fig. 1E, F, G, H, I, J, $\mathrm{K}$ and L). Moreover, 'Huashuo' seeds were significantly less mature than 'Huajin' seeds in October (the seed coat color of the former had not completely changed) (Fig. 1H3). The growth of oil-tea tree fruits was apparent based on the continuous increase in lateral diameter and longitudinal diameter. Fruits of 'Huashuo' had a relatively larger lateral diameter, whereas those of 'Huajin' had a larger longitudinal diameter, which contributed to 

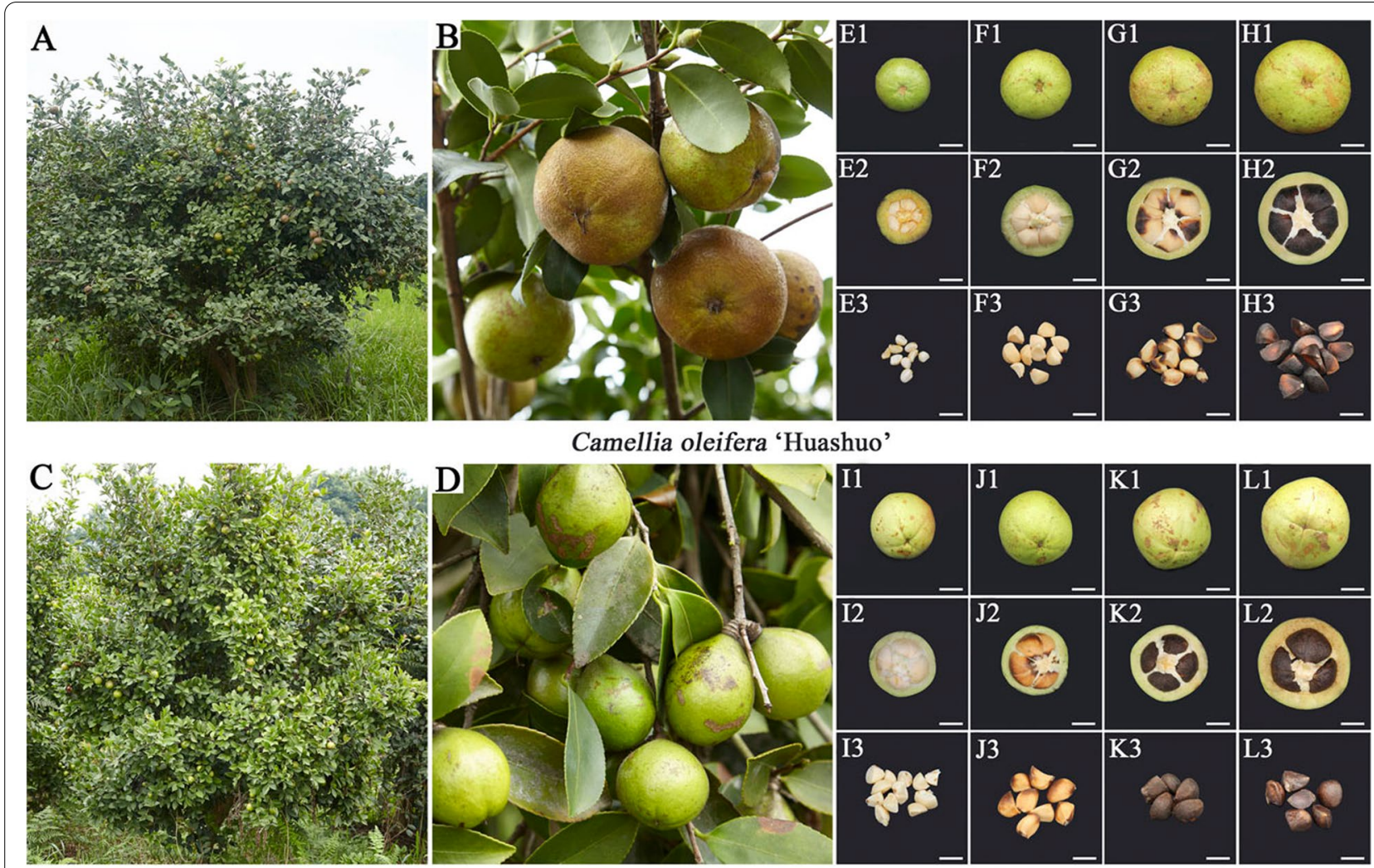

\section{Camellia oleifera 'Huajin'}

Fig. 1 Camellia oleifera 'Huashuo' and 'Huajin' cultivars and their fruit development. A Tree body of C. oleifera'Huashuo'. B Fruits of C. oleifera 'Huashuo'. C Tree body of C. oleifera 'Huajin'. D Fruits of C. oleifera'Huajin.' E Fruit development in C. oleifera'Huashuo' in July. F Fruit development in C. oleifera'Huashuo' in August. G Fruit development in C. oleifera 'Huashuo' in September. H Fruit development in C. oleifera 'Huashuo' in October. I Fruit development in C. oleifera 'Huajin' in July. J Fruit development in C. oleifera 'Huajin' in August. K Fruit development in C. oleifera'Huajin' inSeptember. L Fruit development in C. oleifera'Huajin' in October. (1) Whole fruits of C. oleifera. (2) Cross-sections of C. oleifera fruit. (3) Seeds of C. oleifera. Scale bars, $10 \mathrm{~mm}$

their distinct fruit shapes. In addition, the fruit shape index of 'Huashuo' gradually increased, which indicated that the fruits grew horizontally mainly along a horizontal axis (Table 1).

\section{Fruit development phenotypic traits}

The growth and development of oil-tea tree fruits were accompanied by increased fruit weight (FW), fresh seed weight (FSW), dry seed weight (DSW), fresh seed kernel

Table 1 The fruit shape index of Camellia oleifera 'Huashuo' and 'Huajin' cultivars

\begin{tabular}{lllll}
\hline Cultivars & Periods & Lateral diameter / mm & \multicolumn{1}{l}{$\begin{array}{l}\text { Longitudinal diameter } \\
\text { / } \mathbf{m m}\end{array}$} & Fruits shape index \\
\hline Camellia oleifera'Huashuo' & July & $29.18 \pm 1.84 \mathrm{Bd}$ & $25.69 \pm 3.78 \mathrm{Bc}$ & $1.15 \pm 0.11 \mathrm{Ab}$ \\
& August & $41.50 \pm 2.66 \mathrm{Ac}$ & $34.68 \pm 2.52 \mathrm{Bb}$ & $1.20 \pm 0.06 \mathrm{Aab}$ \\
& September & $45.45 \pm 3.10 \mathrm{Ab}$ & $37.99 \pm 2.19 \mathrm{Ba}$ & $1.20 \pm 0.04 \mathrm{Aab}$ \\
& October & $49.01 \pm 3.79 \mathrm{Aa}$ & $39.56 \pm 2.78 \mathrm{Ba}$ & $1.24 \pm 0.07 \mathrm{Aa}$ \\
Camellia oleifera'Huajin' & July & $33.62 \pm 3.62 \mathrm{Ac}$ & $40.65 \pm 3.40 \mathrm{Ad}$ & $0.83 \pm 0.07 \mathrm{Bb}$ \\
& August & $39.13 \pm 2.81 \mathrm{Bb}$ & $43.41 \pm 2.60 \mathrm{Ac}$ & $0.90 \pm 0.04 \mathrm{Ba}$ \\
& September & $39.78 \pm 2.43 \mathrm{Bab}$ & $45.95 \pm 2.85 \mathrm{Ab}$ & $0.87 \pm 0.07 \mathrm{Bab}$ \\
& October & $41.62 \pm 3.51 \mathrm{Ba}$ & $49.06 \pm 2.94 \mathrm{Aa}$ & $0.85 \pm 0.08 \mathrm{Bb}$ \\
\hline
\end{tabular}

Data are represented as the mean values \pm standard error $(\mathrm{SE} ; n=15)$. Different uppercase and lowercase letters indicate significant differences $(P \leq 0.05 ;$ Duncan's multiple range tests) between cultivars and periods, respectively 
weight (FKW) and dry seed kernel weight (DKW), as well as decreased seed water content (SWC) and seed kernel water content (KWC). The FSW, DSW, FKW and DKW in C. oleifera 'Huajin' were significantly higher than those in C. oleifera 'Huashuo' in July (by 224.56, 233.33, 334.78 and $657.14 \%$, respectively). The FSW and FKW in 'Huashuo' were greater than those in 'Huajin' in both September and October, but the DSW and DKW in 'Huashuo' were lower than those in 'Huajin'. This indicated that the dry mass contents of both seeds and seed kernels in 'Huashuo' were lower compared with 'Huajin'. Furthermore, the SWC and KWC in 'Huashuo' were consistently higher than those in 'Huajin' each given period. In October in particular, when the fruits were nearly mature, the SWC and KWC were significantly higher in 'Huashuo' (by 24.52 and $31.36 \%$, respectively) compared to 'Huajin' $(P \leq 0.05)$ (Table 2). These results showed that 'Huajin' fruits were more mature than those of 'Huashuo' for each given period.

\section{Nutrient content}

Seed oil content (SOC) and seed kernel oil content (KOC) increased throughout development, whereas soluble sugar content (SSC) and starch content (SC) decreased (Fig. 2). Oil had formed in the seeds and seed kernels of $C$. oleifera 'Huajin' in July but could not be extracted from $C$. oleifera 'Huashuo' in the same month. The SOC and KOC in 'Huajin' were significantly higher than those in 'Huashuo' $(P \leq 0.05)$ for each given period (e.g. by 99.96 and $36.64 \%$, respectively, in October) (Fig. 2A and B). The KOC in 'Huajin' increased by $216.81 \%$ from August to September, and that of 'Huashuo' increased significantly $(P \leq 0.05)$ from September to October (Fig. 2B). The same trend was also observed for SOC (Fig. 2A). The SSC and SC of both cultivars were high in July and gradually decreased over time (Fig. 2C and D). The SSC in 'Huajin' decreased by
47.60\% in August, and that of 'Huashuo' decreased significantly $(P \leq 0.05)$ in September (Fig. $2 C)$. However, the trend in SC for both cultivars was the inverse of the SSC trend from July to September (Fig. 2D). In addition, the SSC in 'Huajin' was significantly lower $(P \leq 0.05)$ than that in 'Huashuo' except in July (Fig. 2C).

\section{Relative fatty acid content}

We measured a total of six fatty acids in oil-tea tree seeds: palmitic acid (PA), stearic acid (SA), oleic acid (OA), linoleic acid (LOA), linolenic acid (LA) and arachidonic acid (AA). The relative contents of PA, SA and LA decreased throughout development (decreasing trend), whereas the relative contents of $\mathrm{OA}$ and AA increased, and that of LOA followed an undulating downward trend (Fig. 3). PA and SA in C. oleifera 'Huajin' began to decline gradually in July, whereas those in C. oleifera 'Huashuo' declined in August (Fig. 3A and B). Relatively PA and LA contents did not change significantly from September to October in 'Huajin' $(P>0.05)$, whereas in 'Huashuo', they decreased by 54.31 and $86.70 \%$, respectively, from September to October $(P \leq 0.05)$ (Fig. $3 \mathrm{~A}$ and $\mathrm{E})$. Moreover, relative OA content did not differ significantly between September and October in 'Huajin' $(P>0.05)$, whereas in 'Huashuo', it increased by $64.89 \%$ from September to October $(P \leq 0.05)$ (Fig. $3 C)$. The trend relative LOA content from August to October for 'Huashuo' closely mirrored that for 'Huajin' from July to September (Fig. 3D). We were unable to detect AA in 'Huashuo' seeds in July and August, and relative AA content did not differ significantly between the two cultivars $(P>0.05)$ (Fig. 3F). OA content in oil-tea tree seeds of two cultivars was the most in October and the rate of oil accumulation was increased the most during July and October (Fig. 3C).

Table 2 Fruit development phenotypic traits of Camellia oleifera'Huashuo' and 'Huajin' cultivars

\begin{tabular}{|c|c|c|c|c|c|c|c|c|}
\hline Cultivars & Periods & $\begin{array}{l}\text { Fruit weight } \\
\text { (FW) / g }\end{array}$ & $\begin{array}{l}\text { Fresh seed } \\
\text { weight (FSW) } \\
\text { /g }\end{array}$ & $\begin{array}{l}\text { Dry seed } \\
\text { wight (DSW) } \\
\text { /g }\end{array}$ & $\begin{array}{l}\text { Fresh seed } \\
\text { kernel weight } \\
(\text { FKW) / g }\end{array}$ & $\begin{array}{l}\text { Dry seed } \\
\text { kernel weight } \\
(\mathrm{DKW}) / \mathrm{g}\end{array}$ & $\begin{array}{l}\text { Seed water } \\
\text { content } \\
\text { (SWC) / \% }\end{array}$ & $\begin{array}{l}\text { Seed kernel } \\
\text { water content } \\
\text { (KWC) / \% }\end{array}$ \\
\hline \multirow{4}{*}{$\begin{array}{l}\text { Camellia oleif- } \\
\text { era'Huashuo' }\end{array}$} & July & $18.11 \pm 2.15 \mathrm{BC}$ & $2.28 \pm 0.50 \mathrm{BC}$ & $0.30 \pm 0.08 \mathrm{Ad}$ & $1.15 \pm 0.32 B C$ & $0.07 \pm 0.02 \mathrm{Ad}$ & $86.94 \pm 1.05 \mathrm{Aa}$ & $94.70 \pm 1.54 \mathrm{Aa}$ \\
\hline & August & $48.47 \pm 4.08 \mathrm{Ab}$ & $15.75 \pm 3.38 \mathrm{Ab}$ & $2.12 \pm 0.54 \mathrm{BC}$ & $7.58 \pm 1.59 \mathrm{Ab}$ & $0.56 \pm 0.14 \mathrm{BC}$ & $86.63 \pm 0.65 \mathrm{Aa}$ & $92.64 \pm 0.40 \mathrm{Aa}$ \\
\hline & September & $54.36 \pm 6.26 \mathrm{Ab}$ & $24.35 \pm 2.67 \mathrm{Aa}$ & $6.40 \pm 1.31 \mathrm{Ab}$ & $15.03 \pm 2.09 \mathrm{Aa}$ & $2.10 \pm 0.28 \mathrm{Bb}$ & $73.24 \pm 6.65 \mathrm{Ab}$ & $86.04 \pm 0.31 \mathrm{Ab}$ \\
\hline & October & $63.67 \pm 5.52 \mathrm{Aa}$ & $25.20 \pm 5.12 \mathrm{Aa}$ & $9.63 \pm 1.05 \mathrm{Aa}$ & $16.40 \pm 2.23 \mathrm{Aa}$ & $4.02 \pm 0.50 \mathrm{Ba}$ & $60.38 \pm 10.02 \mathrm{Ac}$ & $75.15 \pm 4.16 \mathrm{Ac}$ \\
\hline \multirow{4}{*}{$\begin{array}{l}\text { Camellia oleif- } \\
\text { era'Huajin' }\end{array}$} & July & $27.30 \pm 1.62 \mathrm{Ab}$ & $7.40 \pm 0.99 \mathrm{Ac}$ & $1.00 \pm 0.18 \mathrm{Ad}$ & $5.00 \pm 0.78 \mathrm{Ac}$ & $0.53 \pm 0.13 \mathrm{Ac}$ & $86.47 \pm 1.80 \mathrm{Aa}$ & $89.44 \pm 1.66 \mathrm{Ba}$ \\
\hline & August & $40.33 \pm 7.35 \mathrm{Aa}$ & $14.40 \pm 3.87 \mathrm{Ab}$ & $4.50 \pm 1.10 \mathrm{Ac}$ & $9.49 \pm 2.39 \mathrm{Ab}$ & $1.85 \pm 0.56 \mathrm{Ac}$ & $66.15 \pm 14.06 \mathrm{Bb}$ & $78.92 \pm 8.98 \mathrm{Bb}$ \\
\hline & September & $43.17 \pm 4.81 \mathrm{Ba}$ & $16.08 \pm 1.52 \mathrm{Bb}$ & $7.39 \pm 3.48 \mathrm{Ab}$ & $10.32 \pm 4.65 \mathrm{Bb}$ & $3.77 \pm 1.72 \mathrm{Ab}$ & $53.03 \pm 10.11 \mathrm{Bb}$ & $63.48 \pm 2.82 \mathrm{BC}$ \\
\hline & October & $46.62 \pm 5.32 \mathrm{Ba}$ & $20.34 \pm 3.42 \mathrm{Ba}$ & $10.47 \pm 1.84 \mathrm{Aa}$ & $14.54 \pm 2.54 \mathrm{Aa}$ & $6.23 \pm 1.32 \mathrm{Aa}$ & $48.49 \pm 2.55 \mathrm{Bb}$ & $57.21 \pm 3.28 \mathrm{BC}$ \\
\hline
\end{tabular}

Data are represented as the mean values \pm SE $(n=5)$. Different uppercase and lowercase letters indicate significant differences $(P \leq 0.05$; Duncan's multiple range tests) between cultivars and periods, respectively 

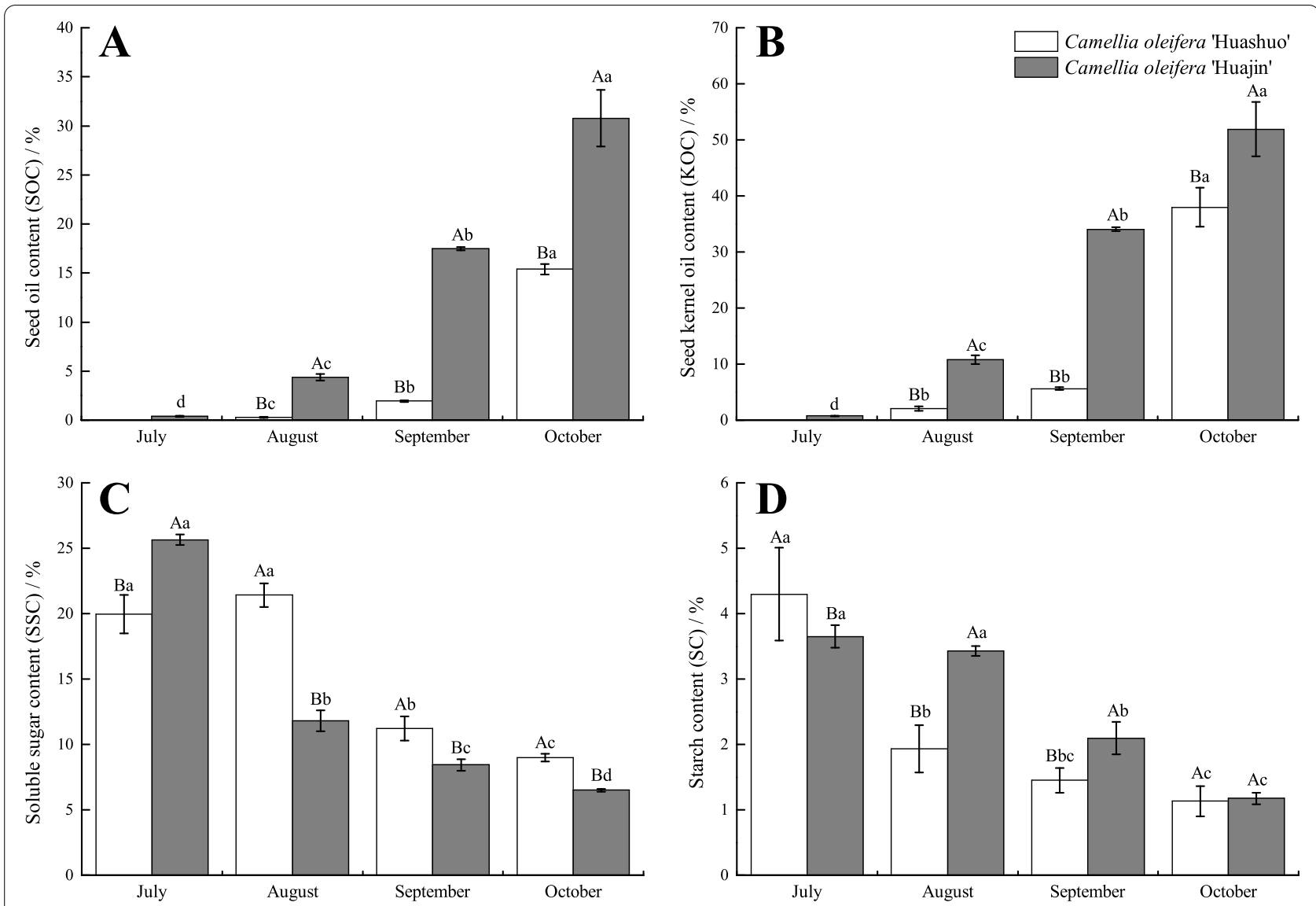

Fig. 2 Nutrient contents in seeds of Camellia oleifera'Huashuo' and 'Huajin' cultivars. Different uppercase and lowercase letters indicate significant differences ( $P \leq 0.05$; Duncan's multiple range tests) between cultivars and periods, respectively. Vertical bars indicate standard errors (SEs) of the mean $(n=3)$

\section{Observation of oil bodies}

Oil bodies gradually formed from the plasm membranes throughout seed development, and spread within the cell until the entire cell was nearly filled with oil (Figs. 4 and 5). There were no oil bodies in C. oleifera 'Huashuo' seed endosperm cells in July, but in C. oleifera 'Huajin', seed endosperm cells contained a layer of oil bodies distributed near to the plasm membrane at this time (Figs. 4A1, $\mathrm{A} 2$ and $\mathrm{A} 3$ and $5 \mathrm{~A} 1$ and $\mathrm{B} 1$ ). Little oil bodies began to appear in 'Huashuo' seed endosperm cells in August (Figs. 4B1, B2 and B3 and 5A2). In addition, the oil bodies in seed endosperm cells were always more noticeable in 'Huajin' than in 'Huashuo' (Figs. 4 and 5). Oil bodies filled the entire seed endosperm cells of 'Huajin' in October, whereas 'Huashuo' seed endosperm cells contained far fewer oil bodies (Figs. 4D1, D2 and D3 and 5A4 and B4).

\section{DEGs and GO functional annotation}

A total of 5,547 DEGs were identified between groups A1 and B1, including 2,315 up-regulated genes and 3,232 down-regulated genes. A total of 5,499 DEGs were identified between A2 and B2, including 3,551 up-regulated genes and 1,948 down-regulated genes. A total of 3,164 DEGs were identified between $\mathrm{A} 3$ and $\mathrm{B} 3$, including 1,869 up-regulated genes and 1,295 down-regulated genes. A total of 1,314 DEGs were identified between A4 and B4, including 618 up-regulated genes and 696 downregulated genes (Fig. 6A). Venn diagrams were used to summarize the number of DEGs among the four different sets, and we found that 249 DEGs were shared among all four (Fig. 6B). Moreover, based on GO functional annotation, we found that the 20 biological processes related to the DEGs could becategorized into three groups: biological process, cellular component and molecular function. The top three GO terms within the biological process category were metabolic process, cellular process and single-organism process. Within the cellular component category, the top three terms were membrane, cell and cell part, and in the molecular function category, the top three terms were catalytic activity, binding and transporter activity (Fig. 6C). 

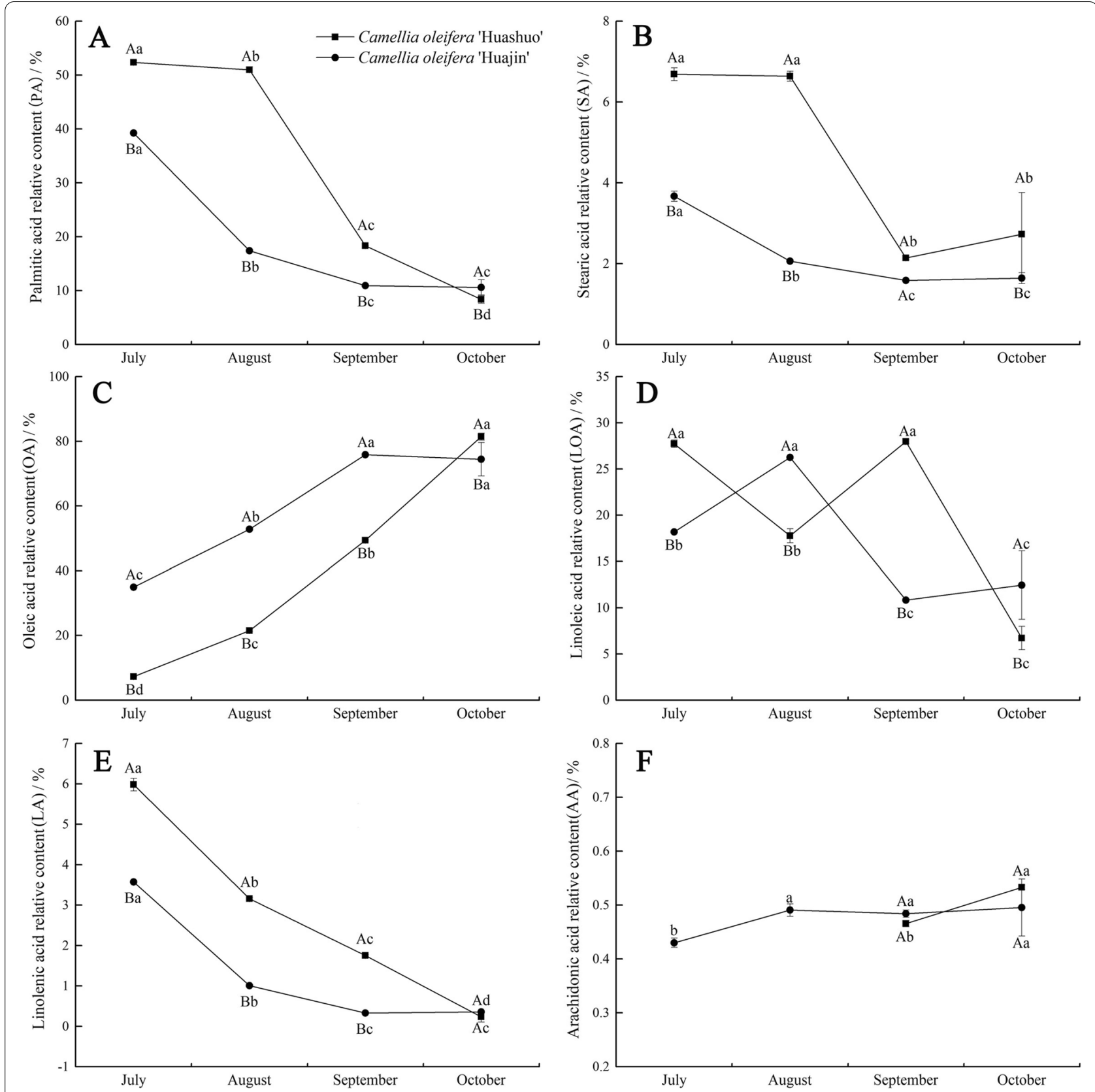

Fig. 3 Relative fatty acid contents in seeds of Camellia oleifera'Huashuo' and 'Huajin' cultivars. Different uppercase and lowercase letters indicate significant differences ( $P \leq 0.05$; Duncan's multiple range test) between cultivars and periods, respectively. Vertical bars indicate SEs of the mean $(n=3)$

\section{Classification of DEGs associated with the fatty acid biosynthesis pathway}

For the fatty acid biosynthesis (ko 00,061) pathway, the associated DEGs could be classified based on 14 KEGG annotations (ACACC, accA, accB, accC, FabD, FabH, FabF, FabG, FabI, FabZ, FAB2, FATA, FATB and FadD). $A$ total of 26, 10, 6 and 3 genes were enriched in the A1-B1, A2-B2, A3-B3 and A4-B4 sets, respectively. To determine differences between the two cultivars in the expression of 26 fatty acid biosynthesis genes, expression levels were analyzed using the $\log _{2}($ FPKM) value. $\log _{2}(\mathrm{~A} 1-\mathrm{B} 1) \geq 1$ indicated that the gene was up-regulated; $-1<\log _{2}(\mathrm{~A} 1-\mathrm{B} 1)<1$ indicated that the difference in expression was not significant; and $\log _{2}(\mathrm{~A} 1-\mathrm{B} 1) \leq-1$ indicated that the gene was down-regulated. Nineteen DEGs were down-regulated in July, accounting for $73.08 \%$ of 

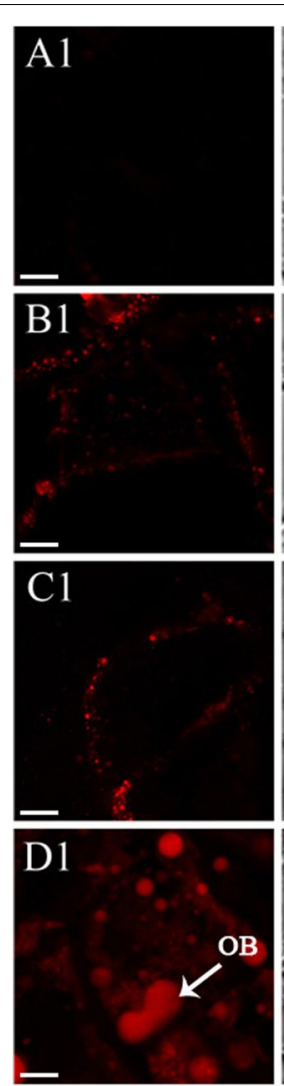

Camellia oleifera 'Huashuo'

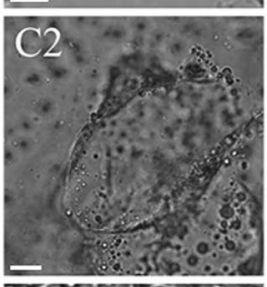

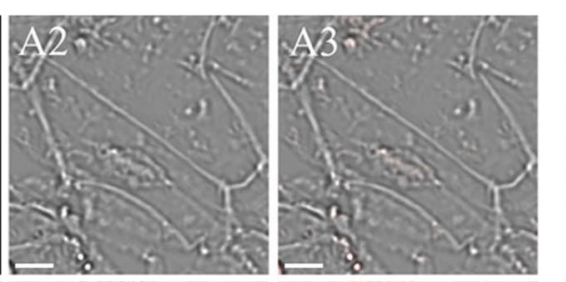
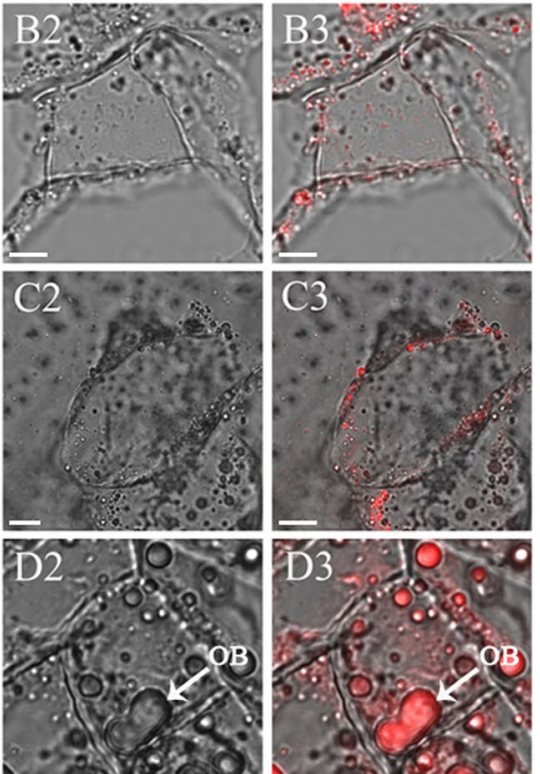

2.s. 2 :
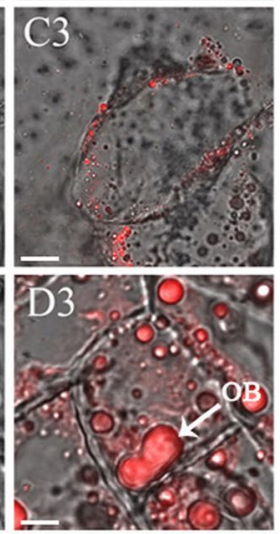
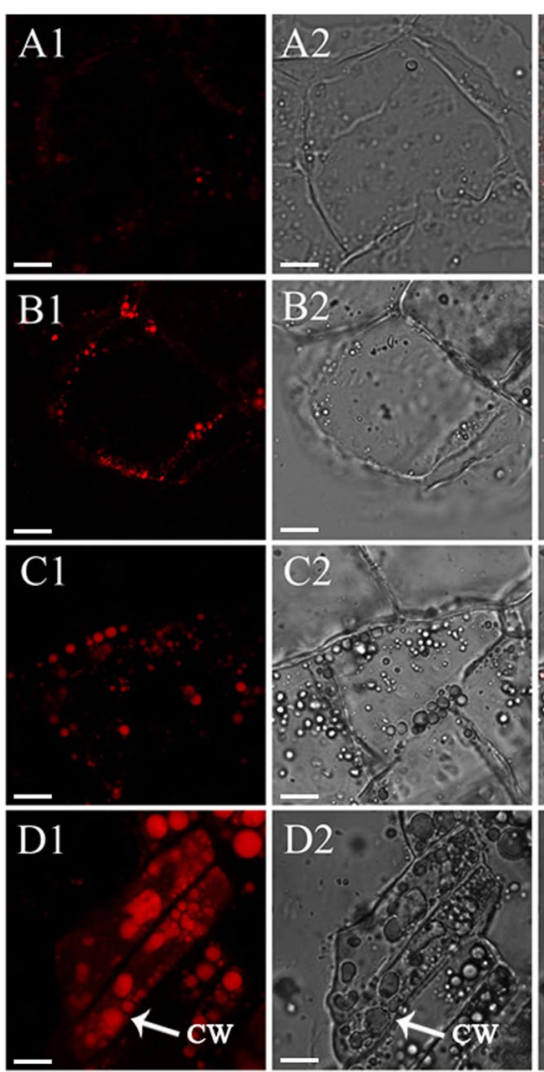

Camellia oleifera 'Huajin'

Fig. 4 Oil bodies in Camellia oleifera 'Huashuo' and 'Huajin' cultivars as observed using laser-scanning confocal microscopy. Oil bodies in (A) July, (B) August, (C) September and (D) October. (1) Oil-body-stained images. (2) White-light images. (3) Merged images. Scale bars: 10 Hm. CW, cell walls; OB, oil bodies

all DEGs in the fatty acid biosynthesis (ko 00,061) pathway, and all DEGs had significant differences in expression. The expression of down-regulated DEGs gradually decreased, and the number of DEGs with non-significant differences gradually increased. The number of downregulated DEGs dropped to zero in October, whereas that of DEGs with insignificant differences rose to 23, accounting for $88.46 \%$ of all DEGs in the fatty acid biosynthesis (ko 00,061) pathway (Table 3 ).

To better understand the relationship between C. oleifera 'Huajin' and C. oleifera 'Huashuo' in terms of fatty acid biosynthesis, gene expression data across different developmental stages were combined into a network. The expression levels of most DEGs (73.08\%) were higher in 'Huajin' than in 'Huashuo' in July. As the fruits developed, the expression levels of these DEGs (except for fabF-2, FAB2-1 and FATB) in the seeds of both cultivars gradually approached similar levels. Most DEGs (57.69\%) were expressed at the highest levels in October. In addition, most DEGs (65.38\%) in 'Huajin' were expressed at high levels in July (the average expression level was 100\% higher than in 'Huashuo'), whereas in 'Huashuo', the expression levels of the DEGs increased by $50 \%$ from July to August (Fig. 7).

\section{Discussion}

The change in seed coat color is a critical phenotypic characteristic in oil-tea tree fruit development. When seed coats begin to turn black, it indicates that the fruits are beginning to mature, and completely black seed coats indicate that the fruits have fully matured [20]. Moreover, the volume and weight of fruits before maturity are indicative of growth status, and volume can be determined by the lateral and longitudinal diameters of the fruit [40]. We found that the coat color of C. oleifera 'Huajin' seeds was always darker than that of C. oleifera 'Huashuo' at each given developmental period, and the lateral diameter, longitudinal diameter and weight of 'Huajin' fruits were significantly higher than those of 'Huashuo' in July. Conversely, previous studies have shown that the volume 


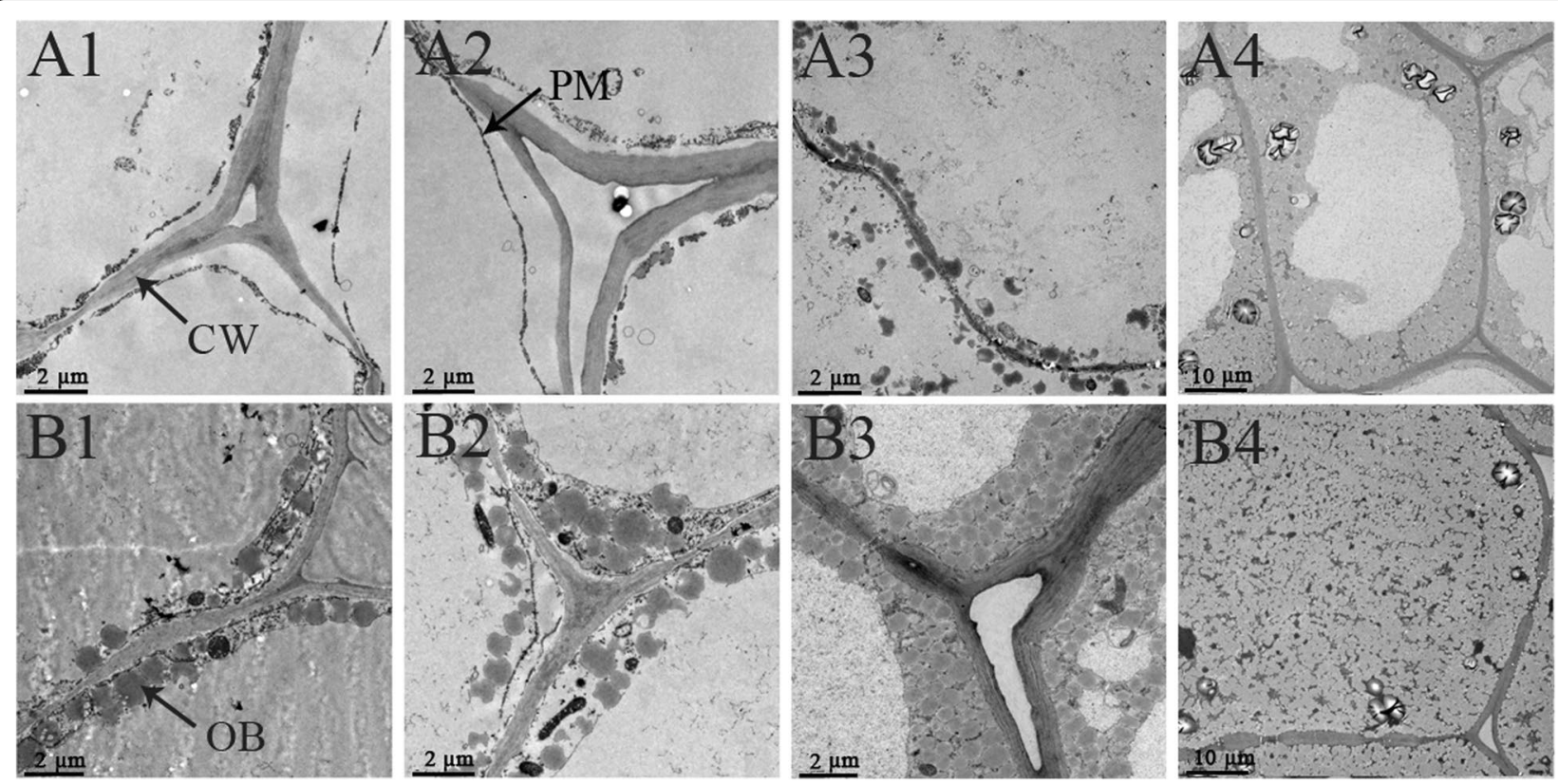

Fig. 5 Oil bodies in Camellia oleifera 'Huashuo' and 'Huajin' cultivars as observed using transmission electron microscopy. Oil bodies in (A) C. oleifera

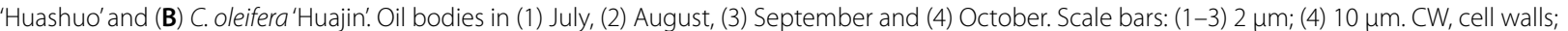
PM, plasm membrane; OB, oil bodies

and weight of fully mature 'Huashuo' fruits far exceeded those of 'Huajin' $[14,15]$. In addition, the SWC in 'Huajin' was always lower than that in 'Huashuo'. The SWC in 'Huashuo' during the Frost's Descent period (October $23-24$ each year) was as high as $60.38 \%$, which was higher than that reported in previous studies [20]. The peak dry weight of seeds is an indicator of physiological maturity [18]. The dehydration stage is when seeds develop to full maturity, and decreased moisture content is accompanied by the accumulation of dry matter, resulting in hard-grained seeds [41-43]. Thus, it was evident that 'Huajin' fruits were more mature within a given developmental period, and the fruit phenotypic characteristics of 'Huashuo' in the Frost's Descent period (October 23-24 each year) were not consistent with those of mature oil-tea tree fruits. In addition, we found that the fastest increased period in fruit weight was the highest temperature and the longest light exposure duration stage, which indicated that higher temperature and longer light exposure might be beneficial to oil-tea tree fruits development. The main reasons were that the fruits of Camellia oleifera need more nutrients and carbohydrates in the expansion stage, and that the photosynthetic efficiency of Camellia oleifera was high in summer due to long illumination time, resulting in continuously fixation of $\mathrm{CO}_{2}$ to form carbohydrates for fruit growth. At the same time, the temperature maintained at about $30{ }^{\circ} \mathrm{C}$ was the most favorable for photosynthesis.
Previous studies have shown that soluble sugar and starch contents of other plants were higher in the early developmental stage of seeds, and gradually degraded with seed development and oil synthesis $[24,25,44]$. The results of the present study were consistent with those precious findings. This might be due to that a large amount of carbohydrates were consumed for the fruit development and oil synthesis [20]. Oil is the most important nutrient in oil-tea tree seeds with respect to their economic value of oil-tea tree [45-47]. The area of oil bodies in cells are positively correlated with the oil content in seeds [28-30]. We were unable to detect oil or oil bodies in C. oleifera 'Huashuo' seeds in July, this is similar to the previous research [36]. This indicated that there was no oil body synthesis in 'Huashuo' fruits before July. We also found that the oil content and the oil bodies in seed endosperm cells in C. oleifera 'Huajin' were always more noticeable than those in 'Huashuo' within a given developmental period. Moreover, in the Frost's Descent period (October 23-24 each year), the seed oil content had already been similar to those reported by previous studies [17]. However, we found that 'Huashuo' seeds contained five fatty acids in July. This suggests that the seed oil contents might have been below the limits of detection for our test methods. It was also possible that the seed coat contained trace amounts of oil [48]. Furthermore, the content of AA could not be measured in 'Huashuo' in July or August. 

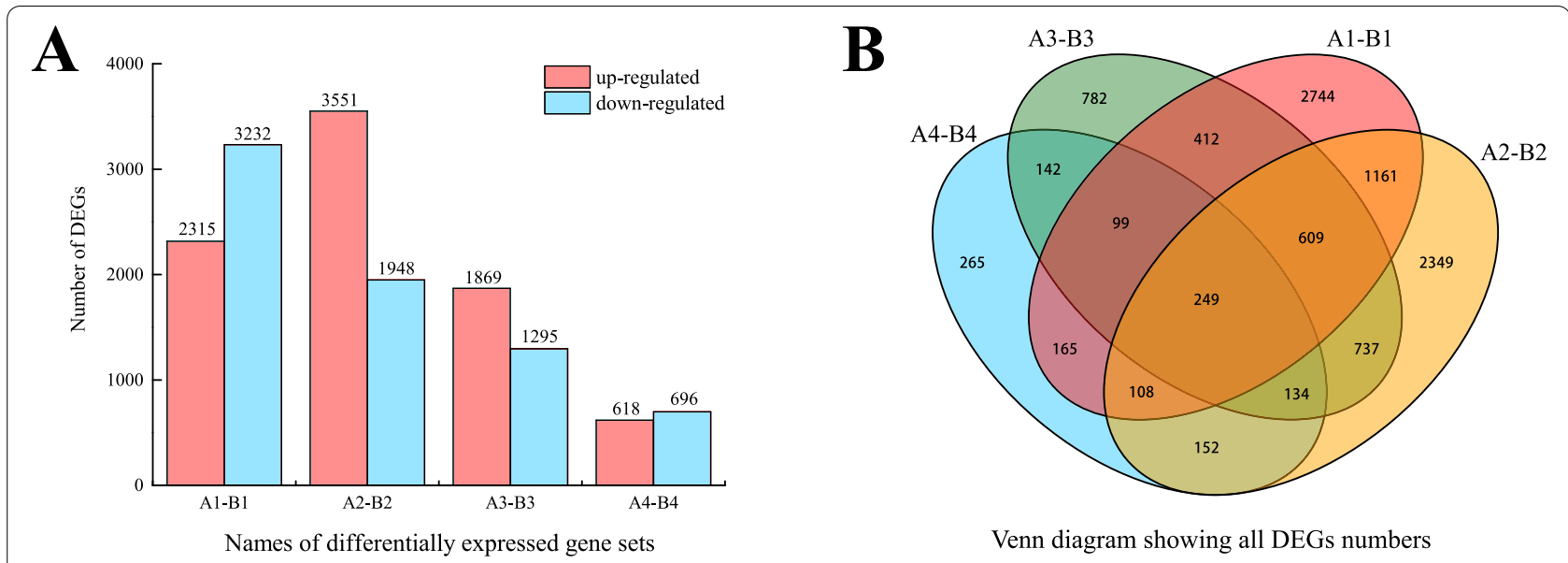

Venn diagram showing all DEGs numbers

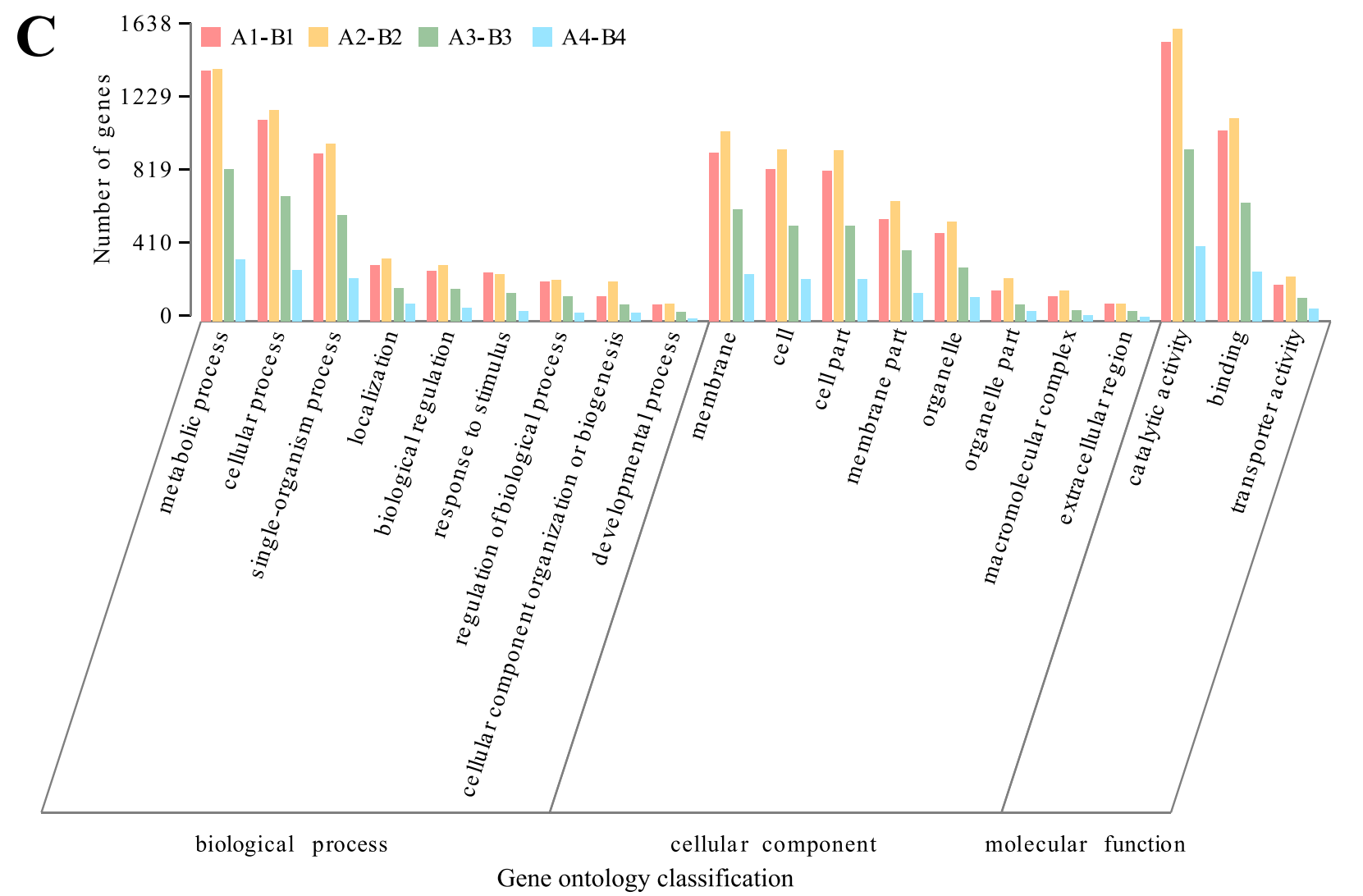

Fig. 6 Differentially expressed genes (DEGs) in Camellia oleifera 'Huashuo' and 'Huajin' cultivars and Gene Ontology (GO) functional annotation at different development periods. A Number of up/down-regulated DEGs at each developmental stage. B Venn diagram showing the DEGs shared among the four gene sets. C GO classification. A1-B1, C. oleifera 'Huajin' seeds in July vs. C. oleifera 'Huashuo' seeds in July; A2-B2, C. oleifera 'Huajin' seeds in August vs. C. oleifera'Huashuo' seeds in August; A3-B3, C. oleifera'Huajin' seeds in September vs. C. oleifera'Huashuo' seeds in September; A4-B4, C. oleifera'Huajin' seeds in October vs. C. oleifera'Huashuo' seeds in October

Previous studies have shown that AA can generally be measured at the middle stage of oil-tea tree seed development $[20,39,49,50]$. These results were consistent with the observation that 'Huajin' fruits were more mature than 'Huashuo' fruits in the Frost's Descent period (October 23-24 each year).
Oil is stored in oil-tea tree seeds mainly in the form of triacylglycerol, which is composed of one molecule of glycerol and three molecules of fatty acids [23, 51]. Bao et al. [52] showed that lipid accumulation was limited by fatty acid content in developing embryos. Therefore, fatty acid biosynthesis is an important factor 
Table 3 Classification of differentially expressed genes (DEGs) associated with the fatty acid biosynthesis pathway

\begin{tabular}{|c|c|c|c|c|c|}
\hline KEGG annotation & ko name & $\log _{2}(A 1-B 1)$ & $\log _{2}(A 2-B 2)$ & $\log _{2}(A 3-B 3)$ & $\log _{2}(A 4-B 4)$ \\
\hline \multirow{2}{*}{ ACACC (Acetyl-CoA carboxylase) } & ACACA-1 & 1.17 & -0.10 & 0.02 & 0.35 \\
\hline & ACACA-2 & 1.48 & 0.64 & 0.80 & -0.09 \\
\hline accA (Acetyl-coenzyme A carboxylase carboxyl transferase subunit alpha) & accA & -3.01 & -0.78 & -1.56 & -0.13 \\
\hline \multirow[t]{2}{*}{ accB (Biotin carboxyl carrier protein of acetyl-CoA carboxylase) } & accB-1 & -4.08 & -0.26 & 0.64 & 0.46 \\
\hline & accB-2 & -1.75 & -0.91 & -0.14 & -0.12 \\
\hline accC (Biotin carboxylase) & accC & -1.26 & -0.87 & 0.24 & 0.27 \\
\hline FabD (Malonyl-CoA: ACP transacylase) & fabD & -1.10 & -0.23 & 0.27 & 0.23 \\
\hline \multirow[t]{2}{*}{ FabH (Ketoacyl-ACP synthase III) } & $\mathrm{fabH}-1$ & -1.77 & -0.53 & 0.11 & 0.06 \\
\hline & $\mathrm{fabH}-2$ & -1.16 & -0.26 & 0.59 & 0.06 \\
\hline \multirow[t]{3}{*}{ FabF (3-oxoacyl-[acyl-carrier-protein] synthase) } & fabF-1 & -4.61 & -0.61 & 1.09 & 0.70 \\
\hline & fabF-2 & 2.69 & 2.77 & 1.68 & 1.18 \\
\hline & fabF-3 & -1.16 & -1.50 & -0.50 & -0.05 \\
\hline \multirow[t]{3}{*}{ FabG (3-oxoacyl-[acyl-carrier-protein] reductase) } & fabG-1 & -1.27 & -0.76 & 0.09 & 0.07 \\
\hline & fabG-2 & -2.59 & -1.22 & 0.09 & 0.14 \\
\hline & fabG-3 & 7.52 & 0.89 & -0.11 & -0.31 \\
\hline Fabl (Enoyl-[acyl-carrier-protein] reductase) & fabl & -2.77 & -1.03 & -0.02 & -0.22 \\
\hline FabZ (3-hydroxyacyl-[acyl-carrier-protein] dehydratase) & fabz & -1.57 & -0.81 & -0.09 & -0.05 \\
\hline \multirow[t]{5}{*}{ FAB2 (Stearoyl-[acyl-carrier-protein] 9-desaturase) } & FAB2-1 & -2.60 & 0.31 & 3.76 & 1.12 \\
\hline & FAB2-2 & 2.08 & -1.53 & -1.74 & -0.31 \\
\hline & FAB2-3 & -3.02 & 2.37 & 0.86 & 0.32 \\
\hline & FAB2-4 & -3.18 & -1.47 & -0.16 & 0.64 \\
\hline & FAB2-5 & -1.40 & 2.13 & 0.75 & 0.93 \\
\hline FATA (Oleoyl-acyl carrier protein thioesterase) & FATA & -1.06 & -0.58 & -0.66 & 0.33 \\
\hline FATB (Acyl acyl-carrier-protein thioesterase type B) & FATB & 2.92 & 2.76 & 1.55 & 2.04 \\
\hline \multirow[t]{2}{*}{ FadD (Long chain acyl-CoA synthetase) } & fadD-1 & -2.98 & -1.39 & -0.36 & 0.32 \\
\hline & fadD-2 & 1.01 & -0.28 & 0.79 & -0.10 \\
\hline Up-regulated & & 7 & 4 & 4 & 3 \\
\hline Down-regulated & & 19 & 6 & 2 & 0 \\
\hline Unchanged & & 0 & 16 & 20 & 23 \\
\hline
\end{tabular}

KEGG Kyoto Encyclopedia of Genes and Genomes

determining the content of plant oil. Previous studies have shown that increased expression of accA (acetylcoenzyme A carboxylase carboxyl transferase subunit alpha), accB (biotin carboxyl carrier protein of acetylCoA carboxylase) and acc (biotin carboxylase) may increase the synthesis of fatty acids and oil [53], and that oil content in mature rapeseed seeds as estimated via antisense expression was significantly lower than that in wild type seeds [54]. Moreover, increased FadD (long chain acyl-CoA synthetase) expression is conducive to increased fatty acid synthesis and oil content in seeds [55], and the expression pattern of FadD closely parallels the lipid accumulation profile in developing seeds [56]. In addition, FabD (malonyl-CoA: ACP transacylase), FabH (ketoacyl-ACP synthase III), FabF (3-oxoacyl-[acyl-carrier-protein] synthase), FabZ (3-hydroxyacyl-[acyl-carrier-protein] dehydratase), FabI (enoyl-[acyl-carrier-protein] reductase), FAB2 (stearoyl-[acyl-carrier-protein] 9-desaturase) and FATA (oleoyl-acyl carrier protein thioesterase) were shown in previous studies to catalyse fatty acid biosynthesis [57-62]. The results of present study showed that the expression levels of most DEGs (including accA, accB1, accB-2, accC, fanH-1, fabH-2, fabD, fabF-1, fabF-3, fabZ, fabI, FAB2-1, FAB2-3, FAB2-4, FAB2-5 and fadD1) were higher in C. oleifera 'Huajin' than in C. oleifera 'Huashuo' in July. Expression in 'Huashuo' increased in August, and the DEGs were highly expressed in both cultivars in October. This result was consistent with the conclusion that 'Huashuo' seeds did not produce lipids in July because of the low expression of fatty acid biosynthesis genes. As a consequence, 'Huashuo' lagged behind 'Huajin' in terms of maturity within a given developmental period. Moreover, Wu et al. [39] found that the downregulation expression of FATB and the upregulation expression of SAD were beneficial to the 


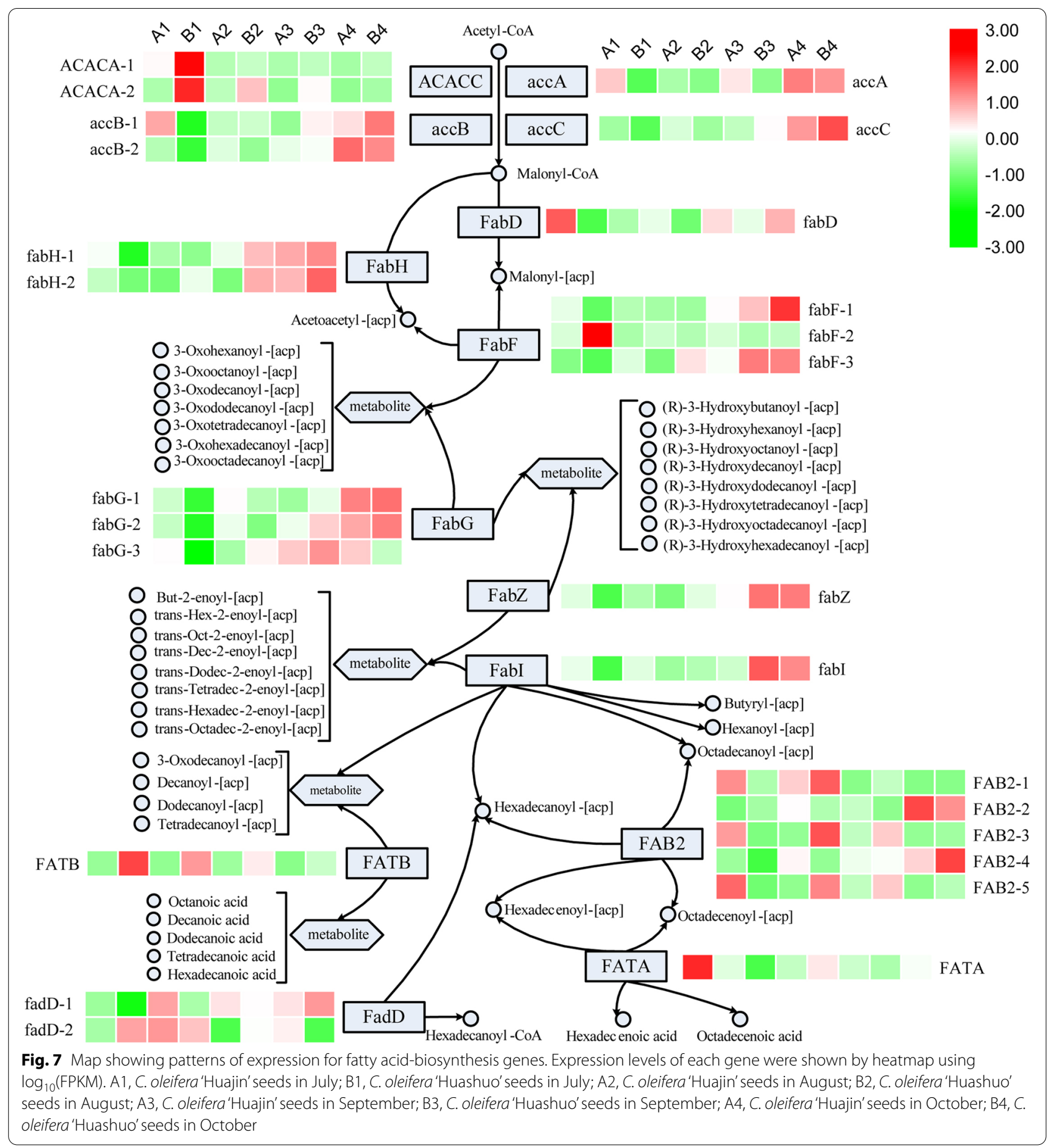

oleic acid synthesis in seeds, which was consistent with our research. The lower expression of FATB and the higher expression of FAB2-1, FAB2-3 and FAB2-5 (FAB2 is a well-characterized SAD [63]) in the early stage of oil synthesis might result in the higher oleic acid in 'Huajin' seeds, which might be the cause of the earlier development of 'Huajin'.

\section{Conclusion}

Our results clearly showed that C. oleifera 'Huashuo' fruits matured slower than $C$. oleifera 'Huajin' fruits. Seeds of 'Huajin' entered the oil synthesis period in July, whereas those of 'Huashuo' did so in August. Moreover, 'Huajin' fruits might have matured by the Frost's Descent period (October 23-24 each year), whereas 'Huashuo' 
fruits had not fully matured by then. However, considering the effects of the climate conditions on fruits development unclear, it was unknown whether 'Huajin' maturity would be advanced or delayed, so further research might be needed.

\section{Methods}

\section{Plant materials}

The different developmental periods fruits of C. oleifera 'Huashuo' and 'Huajin' were collected in the oil-tea tree experimental plot of Central South University of Forestry and Technology, Changsha, Hunan Province, China. The experimental plot was in Dongcheng Town, Wangcheng District, Changsha, Hunan Province, China $\left(113^{\circ} 21^{\prime} \mathrm{E}, 28^{\circ} 05^{\prime} \mathrm{N}\right)$. The climate conditions were shown in the Table S1 (Additional file 1). Sixty trees (thirty trees each cultivar, 10-year-old each tree) without disease and insect infection, suffering no stress, growing well, and showing similar growth potential were selected randomly. The study was conducted from July 2019 to October 2019. The samples were randomly collected from four directions of the trees (the height was consistent, middle of canopy) at July 20, August 20, September 20 and October 24 (the Frost's Descent period) and sixty fruits were collected in each development stage from each cultivar. The seeds were immediately taken out of the fruits (10 fruits each cultivar, selected fruits randomly) and mixed evenly and divided into three portions and frozen with liquid nitrogen. The other fruits were stored in ice box for keeping fresh. After returning to the laboratory, the liquid nitrogen frozen samples were stored at $-80{ }^{\circ} \mathrm{C}$ and the samples stored in the ice box were stored at $-4{ }^{\circ} \mathrm{C}$.

Fifteen fresh fruits were randomly selected to observe and measure shape index. And these fruits were divided into 5 groups (three fruits each group, assigned randomly) to measure the fruit development phenotypic traits. Fifteen fresh fruits were selected randomly from the remaining fruits, and their seeds were placed in the oven (deactivated at $105^{\circ} \mathrm{C}$ for $15 \mathrm{~min}$ and baked at $70{ }^{\circ} \mathrm{C}$ for $72 \mathrm{~h}$ ) after removal of the peel. A small grinder was used to crush the dry seeds, which were then stored in a cool, dry place for the backing experiments (nutrient content and fatty acid measuring). The remaining fresh fruits were stored in a refrigerator at $4{ }^{\circ} \mathrm{C}$ for the backing experiments (oil bodies observation).

\section{Fruit observations and shape index}

A camera (Canon, Japan) was used to photograph fresh fruits and observe, their shapes and cross-sections as well as seeds of the fresh fruits. Vernier calipers were used to measure the lateral and longitudinal diameters of fresh fruits, and fruit shape index was calculated as follows: fruit shape index = lateral diameter / longitudinal diameter. All shape index data in this work are presented as mean \pm standard error (SE) of fifteen biological replicates.

\section{Fruit development phenotypic traits}

An electronic balance was used to measure fresh fruit weight (FW), fresh seed weight (FSW) and fresh seed kernel weight (FKW). Next, each part of the fruit was placed into the oven and dried (deactivated at $105^{\circ} \mathrm{C}$ for $15 \mathrm{~min}$ and baked at $70{ }^{\circ} \mathrm{C}$ for $72 \mathrm{~h}$ ). An electronic balance was then used to measure dry seed weight (DSW) and dry seed kernel weight (DKW). Seed water content (SWC) and seed kernel water content (KWC) were calculated as follows: SWC $(\%)=(\mathrm{FSW}-\mathrm{DSW}) / \mathrm{FSW}$ $\times 100 \%, \mathrm{KWC}(\%)=(\mathrm{FKW}-\mathrm{DKW}) / \mathrm{FKW} \times 100 \%$. All data on fruit development phenotypic traits in this work are presented as the mean $\pm \mathrm{SE}$ of five biological replicates.

\section{Nutrient content}

Soluble sugar content (SSC) and starch content (SC) were determined using the anthrone-ethyl acetate method [64, 65]. Seed samples $(0.1 \mathrm{~g})$ were extracted with $80 \%(\mathrm{v} / \mathrm{v})$ ethanol at $80{ }^{\circ} \mathrm{C}$ for $30 \mathrm{~min}$, and the extract was then centrifuged at $3,500 \mathrm{r} \cdot \mathrm{min}^{-1}$ for $10 \mathrm{~min}$. The extraction process was repeated two more times using $80 \%$ ethanol, then the three supernatants were combined, and $80 \%$ ethanol was added to make up a total volume of $25 \mathrm{~mL}$. The precipitate was combined with $2 \mathrm{~mL}$ of distilled water after the removal of ethanol, and the samples were then incubated at $100{ }^{\circ} \mathrm{C}$ for $15 \mathrm{~min}$. Starch was hydrolyzed by separately adding $9.2 \mathrm{~mol} \cdot \mathrm{L}^{-1}$ and $4.6 \mathrm{~mol} \cdot \mathrm{L}^{-1} \mathrm{HClO} 4$ to the samples. Next, the extract was centrifuged at $4,000 \mathrm{r} \cdot \mathrm{min}^{-1}$ for $10 \mathrm{~min}$, and the precipitate was washed twice. The supernatants were combined to make up a total volume of $50 \mathrm{~mL}$. SSCs and SCs were determined spectrophotometrically with ethyl-anthrone reagent at a wavelength of A630 $\mathrm{nm}$. Total SSC $\left(\mathrm{C}_{\mathrm{SSC}}\right)$ and SC $\left(\mathrm{C}_{\mathrm{SC}}\right)$ in each sample was determined from a standard curve plotted using glucose. SSC and SC were then calculated as follows: SSC $(\%)=\left[\mathrm{C}_{\mathrm{SSC}} \times\right.$ extraction volume $(\mathrm{mL}) \times$ dilution factor $] /$ [sample weight $(\mathrm{g}) \times$ sample volume drawn during measurement $\left.(\mathrm{mL}) \times 10^{6}\right] \times 100 \%$, SC $(\%)=\left[C_{\mathrm{SC}} \times\right.$ extraction volume $(\mathrm{mL}) \times$ dilution factor $\times 0.9] /$ [sample weight $(\mathrm{g}) \times$ sample volume drawn during measurement $\left.(\mathrm{mL}) \times 10^{6}\right] \times 100 \%$. Seed oil content (SOC) and seed kernel oil content (KOC) were determined using Soxhlet extraction [66]. All nutrient content data in this study are presented as the mean $\pm \mathrm{SE}$ of three biological replicates. 


\section{Fatty acids}

The fatty acid content was determined followed with the guidelines of the Determination of Fatty Acids in Food of National Food Safety Standard in China [67]. The crushed seeds samples $(0.1 \mathrm{~g})$ were weighted into a test tube with a stopper, and $1 \mathrm{~mL} \mathrm{NaOH}-\mathrm{CH}_{3} \mathrm{OH}(5 \%)$ and $1 \mathrm{~mL} \mathrm{~N}$-heptane were added to the sample. The test tube was covered with a stopper, shaken vigorously for $3 \mathrm{~min}$ and heated at $50{ }^{\circ} \mathrm{C}$ for $2 \mathrm{~min}$, and then let it clarity. Thereafter, $10 \mu \mathrm{L}$ acetic acid was added, and the test tube was shaken vigorously to neutralize the sodium hydroxide. Finally, $100 \mu \mathrm{l}$ of the upper layer solution was used for chromatographic analysis. Fatty acids were analyzed using gas chromatography (Shimadzu GC-2014, Shimadzu, Kyoto, Japan). The parameters were as follows: FID detector temperature, $220^{\circ} \mathrm{C}$; chromatographic column, $30 \mathrm{~m} \times 0.25 \mathrm{~mm} \times 0.25 \mu \mathrm{m}$ (Agilent DB-WAX, California, USA); carrier gas, nitrogen; split ratio, 20:1; sample injection volume, $1 \mu \mathrm{L}$; heating process, $170{ }^{\circ} \mathrm{C}$ (5 min), and $220{ }^{\circ} \mathrm{C}\left(10{ }^{\circ} \mathrm{C} / \mathrm{min}\right.$, stay for $\left.10 \mathrm{~min}\right)$. Fatty acids relative content was then calculated as follows: fatty acids relative content $(\%)=($ fatty acid methyl esters peak area $\times$ conversion coefficient of fatty acid methyl esters to fatty acids) / (sum of peak areas of all fatty acid methyl esters $\times$ conversion coefficient of fatty acid methyl esters to fatty acids). All fatty acid content data in this work are presented as the mean $\pm \mathrm{SE}$ of three biological replicates.

\section{Oil body observations}

We used two different methods to observe the oil bodies within seed kernels. The first method was laser-scanning confocal microscopy $[68,69]$. Fresh seed kernels were cut into $2 \mathrm{~mm}^{3}$ pieces, sectioned $(15 \mu \mathrm{m})$ using a freezing microtome (Leica, Germany), dyed using Nile Red for $5 \mathrm{~min}$, and imaged under laser-scanning confocal microscopy (Leica, Germany). The second observation method was transmission electron microscope [9, 70]. Fresh seed kernels were cut into $1 \mathrm{~mm}^{3}$ pieces and fixed in $2.5 \%$ glutaraldehyde solution for $24 \mathrm{~h}$ at $4{ }^{\circ} \mathrm{C}$. After washing three times (15 min each), the tissue was fixed in $1 \%$ osmium tetroxide for $5 \mathrm{~h}$ at room temperature and dehydrated in a graded series of ethanol solutions $(30 \%, 50 \%, 70 \%, 80 \%$, $90 \%, 95 \%, 100 \%, 100 \%$; 1 h each). Next, the sample was soaked in a series of acetone solutions $(25 \%, 50 \%, 75 \%$, $100 \%, 100 \%$, anhydrous ethanol configuration; $30 \mathrm{~min}$ each). The seed kernel samples were then embedded in epoxy resin, placed in an ion sputter coater and gilded for $20 \mathrm{~min}$. Semi-thin Sects. $(0.5 \mu \mathrm{m})$ were cut with a diamond knife using an ultramicrotome (EM UC7, Leica), then mounted on copper grids and dyed using toluidine blue. Imaging was performed using a transmission electron microscope (HT7700, Hitachi, Japan).

\section{Sampling for RNA-seq and RNA preparation}

The oil-tea tree fruits underwent development over a period of 4 months, and fresh seeds were selected for molecular sequencing analyses. The samples were named A1 (C. oleifera 'Huajin' seeds in July), B1 (C. oleifera 'Huashuo' seeds in July), A2 (C. oleifera 'Huajin' seeds in August), B2 (C. oleifera 'Huashuo' seeds in August), A3 (C. oleifera 'Huajin' seeds in September), B3 (C. oleifera 'Huashuo' seeds in September), A4 (C. oleifera 'Huajin' seeds in October), and B4 (C. oleifera 'Huashuo' seeds in October). Three samples were selected for each treatment. A total 24 samples were rapidly frozen in liquid nitrogen and stored at $-80{ }^{\circ} \mathrm{C}$. The purity, concentration, and integrity of the RNA samples were assessed using agarose gel electrophoreses and the Nanodrop 2500 instrument (Thermo Fisher Scientific, USA) to ensure that they were suitable for transcriptome sequencing $[4,31]$.

\section{Library preparation and RNA-seq}

RNA samples were sent to Shanghai Meiji Biomedical Technology Co., Ltd. (Shanghai, China), where the libraries were produced and sequenced. RNA-seq transcriptome libraries were prepared with a TruSeq ${ }^{\mathrm{TM}}$ RNA Sample Preparation kit from Illumina (USA) using $1 \mu \mathrm{g}$ of total RNA. Shortly, thereafter, mRNA was isolated using the polyA selection method with oligo $(\mathrm{dT})$ beads and fragmented with fragmentation buffer. Double-stranded cDNA was synthesized using a SuperScript Doublestranded cDNA Synthesis kit (Invitrogen, USA) with random hexamer primers (Illumina). The synthesized cDNA was then subjected to end-repair, phosphorylation and ' $A$ ' base addition according to Illumina's library construction protocol. Libraries were size selected for cDNA target fragments of 200-300 bp in 2\% Low Range Ultra agarose followed by polymerase chain reaction (PCR) amplification using Phusion DNA polymerase (NEB) for 15 PCR cycles. After quantification by TBS380, paired-end RNAseq libraries were sequenced with the Illumina HiSeq xten/NovaSeq 6000 Sequencer $(2 \times 150$ bp read length).

\section{Differential expression analysis and functional enrichment}

To identify differentially expression genes (DEGs) among samples, the expression level of each transcript was calculated according to the fragments per kilobase of exon per million mapped reads (FPKM) method. RNA-Seq by Expectation-Maximization (RSEM) (http://deweylab. biostat.wisc.edu/rsem/) [71] was used to quantify gene transcript abundances. The $\mathrm{R}$ package EdgeR (Empirical analysis of Digital Gene Expression in R (http://www. bioconductor.org/packages/2.12/bioc/html/edgeR.html) [72] was used for differential expression analysis. Functional enrichment analysis, including Gene Ontology (GO) and Kyoto Encyclopedia of Genes and Genomes 
(KEGG) analyses, was performed to identify which GO terms and metabolic pathways were significantly enriched for the DEGs at Bonferroni-corrected $P$-values $\leq 0.05$ compared with the whole-transcriptome background. GO functional enrichment and KEGG pathway analyses were carried out using Goatools (https://github. com/tanghaibao/Goatools) and KOBAS (http://kobas. cbi.pku.edu.cn/home.do) [73].

\section{Statistical analysis}

Microsoft Office Excel 2013 was used to process the data. Origin 9.0 was used to create the plots, and SPSS 19.0 software was used to test for significant differences. Treatment means were compared using one-way analysis of variance and Duncan's multiple range tests with $P$-values $\leq 0.05$ indicating significant differences. Transcriptome data were analyzed using the free online Majorbio cloud platform (www.majorbio.com).

\section{Abbreviations}

FW: Fruit weight; FSW: Fresh seed weight; DSW: Dry seed weight; FKW: Fresh seed kernel weight; DKW: Dry seed kernel weight; SWC: Seed water content; KWC: Seed kernel water content; SOC: Seed oil content; KOC: Seed kernel oil content; SSC: Soluble sugar content; SC: Starch content; PA: Palmitic acid; SA: Stearic acid; OA: Oleic acid; LOA: Linoleic acid; LA: Linolenic acid; AA: Arachidonic acid; DEGs: Differentially expression genes; GO: Gene Ontology; KEGG: Kyoto Encyclopedia of Genes and Genomes.
\end{abstract}

\section{Supplementary Information}

The online version contains supplementary material available at https://doi. org/10.1186/s12870-021-03114-2.

Additional file 1. Climate conditions of July to October in 2019 in Changsha, Hunan, China.

\section{Acknowledgements}

We thank Shanghai Meiji Biomedical Technology Co., Ltd. (Shanghai, China) for its service in RNA-Seq and transcriptome analysis. We thank Textcheck (Florida USA) for its service in language help. We thank Dr. Zhiming Liu (Eastern New Mexico University, USA) and Dr. Heping Cao (U.S. Department of Agriculture, USA) for their assistance in revising the manuscript.

\section{Authors' contributions}

F.Z., Z.L. and X.T. designed the entire experiment. X.T., F.Z. and Y.G. prepared the plant materials and collected the samples. F.Z. and J.Z. analyzed the results. F.Z. and Z.L. wrote the main manuscript text. All authors have read and approved the manuscript.

\section{Funding}

This work was supported by the Major Projects of Science and Technology Project of Hunan Province (2018NK1030). The funders had no role in study design, data collection and analysis, decision to publish, or preparation of the manuscript.

\section{Availability of data and materials}

The sequence datasets generated and/or analyzed during the current study are available in the NCBI repository, https://www.ncbi.nlm.nih.gov/bioproject/ PRJNA693152. The other datasets used and/or analyzed during the current study are available from the corresponding author on reasonable request.

\section{Declarations}

Ethics approval and consent to participate

Authors confirmed that experimental research on plants, including collection of plant material, complied with institutional, national, or international guidelines. The field studies were conducted in accordance with local legislation. Authors complied with the Convention on the Trade in Endangered Species of Wild Fauna and Flora: https://www.cites.org/.

\section{Consent for publication}

Not applicable.

\section{Competing interests}

The authors declare that they have no conflict of interest to this work.

\section{Author details}

${ }^{1}$ Key Laboratory of Cultivation and Protection for Non-Wood Forest Trees, Ministry of Education, Central South University of Forestry and Technology, Changsha 410004, Hunan, China. ${ }^{2}$ Centre of Pear Engineering Technology Research, State Key Laboratory of Crop Genetics and Germplasm Enhancement, Nanjing Agricultural University, Nanjing 210095, Jiangsu, China. ${ }^{3}$ Engineering Technology Research Center of Southern Hilly and Mountainous Ecological Non-Wood Forestry Industry of Hunan Province, Central South University of Forestry and Technology, Changsha 410004, Hunan, China.

Received: 15 January 2021 Accepted: 22 June 2021

Published online: 23 July 2021

\section{References}

1. Wen Y, Su S-C, Ma L-Y, Wang X-N. Effects of gibberellic acid on photosynthesis and endogenous hormones of Camellia oleifera Abel. in 1st and 6th leaves. J Forest Res. 2018;23(5):309-17.

2. Chen J, Yang X, Huang X, Duan S, Long C, Chen J, Rong J. Leaf transcriptome analysis of a subtropical evergreen broadleaf plant, wild oil-tea camellia (Camellia oleifera), revealing candidate genes for cold acclimation. Bmc Genomics. 2017;18(1):211.

3. Xiao Z, Zhang Z, Krebs CJ. Seed size and number make contrasting predictions on seed survival and dispersal dynamics: a case study from oil tea Camellia oleifera. Forest Ecol Manage. 2015;343:1-8.

4. Wu L, Li J, Li Z, Zhang F, Tan X. Transcriptomic analyses of Camellia oleifera 'Huaxin' leaf reveal candidate genes related to long-term cold stress. Int J Mol Sci. 2020;21(3):846.

5. Yue W, Su SC, Ma LY, Yang SY, Wang XN. Effects of canopy microclimate on fruit yield and quality of Camellia oleifera. Sci Hortic. 2018;235:132-41.

6. Snyder JM, Mounts TL, Holloway RK. An analysis scheme for estimation of crude oil quality. J Am Oil Chem Soc. 1991;68(5):285-8.

7. Li Z, Tan X, Liu Z, Lin Q, Wu L. In vitro propagation of camellia oleifera abel Using hypocotyl, cotyledonary node, and radicle explants. Hortsci Publ Am Soc Horticult Sci. 2016;51(4):416-21.

8. Qu X, Zhou J, Masabni J, Yuan J. Phosphorus relieves aluminum toxicity in oil tea seedlings by regulating the metabolic profiling in the roots. Plant Physiol Biochem. 2020;152:12-22.

9. Chao G, Yuan D, Yang Y, Wang B. Pollen tube growth and double fertilization in Camellia oleifera. J Am Soc Hortic Sci Am Soc Hortic Sci. 2015;140(1):12-8.

10. Lee CP, Yen GC. Antioxidant activity and bioactive compounds of tea seed (Camellia oleifera Abel.) oil. J Agric Food Chem. 2006;54(3):779-84.

11. Cheng Y-T, Lu C-C, Yen G-C. Beneficial effects of camellia oil (Camellia oleifera Abel.) on hepatoprotective and gastroprotective activities. J Nutr Sci Vitaminol. 2015;61(Supplement):S100-2.

12. Lee W-T, Tung Y-T, Wu C-C, Tu P-S, Yen G-C. Camellia oil (Camellia oleifera Abel.) modifies the composition of the gut microbiota and alleviates acetic acid-induced colitis in rats. J Agric Food Chem. 2018;66(28):7384-92.

13. Guo N, Tong T, Ren N, Tu Y, Li B. Saponins from seeds of Genus Camellia: phytochemistry and bioactivity. Phytochemistry. 2018;149:42-55.

14. Tan X. An elite variety: camellia oleifera 'Huashuo.' Sci Silvae Sin. 2011:47(12):184-209. 
15. Yuan D. An elite variety:camellia oleifera 'Huajin.' Sci Silvae Sin. 2012;48(2):187-90.

16. Zeng Y, Tan X, Zhang D, Chen H, Chen L. Regulation about control oil synthesis by key genes in fatty acid metabolic pathway of camellia oleifera. J Chin Cereals Oils Assoc. 2014;29(2):26-103.

17. Zeng YL, Yan YD, Tan XF, Chao-Yin HE, Yang R. Effect of air-drying on seed oil yield and component of Camellia oleifera after harvest. Plant Physiol J. 2018;54(02):316-24.

18. Contreras S, Rabara R, Bennett MA, Tay D, Mcdonald M. Acquisition of germination capacity, photosensitivity, and desiccation tolerance in lettuce seeds. Seed Sci Technol. 2008;36(3):667-78.

19. Fu H, Cao DD, Hu WM, Guan YJ, Fu YY, Fang YF, Hu J. Studies on optimum harvest time for hybrid rice seed. J Sci Food Agric. 2017;97(4):1124-33.

20. Wenjing $L$, Ping $X$, Meng C, Yuxin F, Liping L. The growth and development dynamics of Camellia oleifera Abel.fruits and seeds. J Nanchang Univ Nat Sci. 2019;1:46-52.

21. Eastmond PJ, Rawsthorne S. Coordinate changes in carbon partitioning and plastidial metabolism during the development of oilseed rape embryos. Plant Physiol. 2000;122(3):767-74.

22. Yazdi-Samadi B, Rinne RW, Seif RD. Components of developing soybean seeds: oil, protein, sugars, starch, organic acids, and amino acids1. Agron J. 1977;69:481-6.

23. Hauser F, Søndergaard L, Grimmelikhuijzen CJP. Molecular cloning, genomic organization and developmental regulation of a novel receptor from drosophila melanogaster structurally related to gonadotropinreleasing hormone receptors from vertebrates. Biochem Biophys Res Commun. 1998;249(3):822-8.

24. Baud S, Boutin JP, Miquel M, Lepiniec LC, Rochat C. An integrated overview of seed development in Arabidopsis thaliana ecotype WS. Plant Physiol Biochem. 2002;40(2):151-60.

25. Western TL, Haughn SGW. Differentiation of mucilage secretory cells of the arabidopsis seed coat. Plant Physiol. 2000;122(2):345-55.

26. Frey-Wyssling A, Grieshaber E, Mühlethaler K. Origin of spherosomes in plant cells. J Ultrastruct Res. 1963;8(5-6):506-16.

27. Poxleitner M, Rogers SW, Samuels AL, Browse J, Rogers JC. A role for caleosin in degradation of oil-body storage lipid during seed germination. Plant J. 2010;47(6):917-33.

28. Peng CC, Lin IP, Lin CK, Tzen JTC. Size and stability of reconstituted sesame oil bodies. Biotechnol Prog. 2003;19(5):1623-6.

29. Ting JTL, Lee K, Ratnayake C, Platt KA, Huang BAHC. Oleosin genes in maize kernels having diverse oil contents are constitutively expressed independent of oil contents. Planta. 1996;199(1):158-65.

30. Hu Z, Wang X, Zhan G, Liu G, Hua W, Wang H. Unusually large oilbodies are highly correlated with lower oil content in Brassica napus. Plant Cell Rep. 2009;28(4):541.

31. Zhou J, Lu M, Yu S, Liu Y, Tan X. In-depth understanding of camellia oleifera self-incompatibility by comparative transcriptome, proteome and metabolome. Int J Mol Sci. 2020;21(5):1600.

32. An M, Deng M, Zheng SS, Song YG. De novo transcriptome assembly and development of SSR markers of oaks Quercus austrocochinchinensis and Q. kerrii (Fagaceae). Tree Genet Genom. 2016;12(6):103.

33. Qin Y, Sun H, Hao P, Wang H, Yu S. Transcriptome analysis reveals differences in the mechanisms of fiber initiation and elongation between long- and short-fiber cotton (Gossypium hirsutum L.) lines. BMC Genomics. 2019;20(1):633. https://doi.org/10.1186/s12864-019-5986-5.

34. Jiang N, Tan X, Zhang L, Zeng Y. Gene analysis of a-Linolenic acid metabolism of camellia oleifera seeds based on RNA-Seq. Scientia Silyae Sinicae. 2014;50(8):68-75.

35. Zeng $Y$, Tan $X$, Zhang L, Jiang N, Cao H. Identification and expression of Fructose-1,6-bisphosphate aldolase genes and their relations to oil content in developing seeds of tea oil tree (Camellia oleifera). Plos One. 2014;9(9):e107422.

36. Gong W, Song Q, Ji K, Gong S, Wang L, Chen L, Zhang J, Yuan D. Fulllength transcriptome from camellia oleifera seed provides insight into the transcript variants involved in oil biosynthesis. J Agric Food Chem. 2020;68(49):14670-83.

37. Peng S, Lu J, Zhang Z, Ma L, Liu C, Chen Y. Global transcriptome and correlation analysis reveal cultivar-specific molecular signatures associated with fruit development and fatty acid determination in camellia oleifera abel. Int J Genom. 2020:6162802. https://doi.org/10.1155/2020/ 6162802.
38. Ping L, Kailiang W, Changfu Z, Yunhai X, Xiaohua Y, Hengfu Y. Seed transcriptomics analysis in camellia oleifera uncovers genes associated with oil content and fatty acid composition. Int J Mol Sci. 2018;19(1):118.

39. Wu B, Ruan C, Han P, Ruan D, Xiong C, Ding J, Liu S. Comparative transcriptomic analysis of high-and low-oil Camellia oleifera reveals a coordinated mechanism for the regulation of upstream and downstream multigenes for high oleic acid accumulation. 3 Biotech. 2019;9(7):257. https://doi.org/10.1007/s13205-019-1792-7.

40. Chen Y, Xiao Z, Peng S, Yang X, Li D, Wang X, Duan W. Study of fruit growing specialties and its oil content in oil-tea camellia. Forest Res. 2006;019(1):9-14.

41. Balla E. Effect of moisture content and maturity on hardseededness and germination in okra (Abelmoschus esculentus L. Moench). Int J Plant Physiol Biochem. 2011;3(6):102-7.

42. Qin GC, Wang QT, Hu J, Li Z, He F, Wang JC. Changes in seed quality and ABA content during seed development in sponge gourd (Luffa cylindrica). Seed Sci Technol. 2013:41(41):398-406.

43. Demirbas A. Potential resources of non-edible oils for biodiesel. Energy Sources Part B Econ Plann Policy. 2009;4(3):310-4.

44. Periappuram C. The plastidic phosphoglucomutase from arabidopsis. A reversible enzyme reaction with an important role in metabolic control. Plant Physiol. 2000;122(4):1193-200.

45. Voelker T, Kinney AJ. Variations in the biosynthesis of seed-storage lipids. Ann Rev Plant Physiol Plant Mol Biol. 2001;52(52):335-61.

46. Martin Hajduch JEC, Hurrelmeyer EK, Song Z, Agrawal GK, Thelen JJ. Proteomic analysis of seed filling in Brassica napus. Developmental characterization of metabolic isozymes using high-resolution two-dimensional gel electrophoresis. Plant Physiol. 2006;141(1):1159-1159.

47. Lee CP, Shih PH, Hsu CL, Yen GC. Hepatoprotection of tea seed oil (Camellia oleifera Abel.) against CCl4-induced oxidative damage in rats. Food Chem Toxicol. 2007:45(6):888-95.

48. Anthony $\mathrm{HCH}$. Oleosins and oil bodies in seeds and other organs. Plant Physiol. 1996;110(4):1055-61.

49. Wu B, Ruan C, Xiong C, Han P, Zhang G, Ruan D. Analysis of related gene expression patterns of oleic acid synthesis and accumulation in camellia oleifera seed. Mol Plant Breed. 2019;17(05):1493-502.

50. Liu X, Xiao P, Luo H, Huang X, Fu Y, Luo L. Variations in fatty acid composition of camellia oleifera abel. Seeds during development. Modern Food Sci Technol. 2015;31(06):322-8.

51. Bates PD, Johnson SR, Cao X, Li J, Browse J. Fatty acid synthesis is inhibited by inefficient utilization of unusual fatty acids for glycerolipid assembly. Proc Natl Acad Sci U S A. 2014;111(3):1204.

52. Xiaoming $B$, John $O$. Supply of fatty acid is one limiting factor in the accumulation of triacylglycerol in developing embryos. Plant Physiology. 1999;120(4):1057-62.

53. Xiaojie L, Dezhuo P, Jian LI, Shipin C, Wei C. Transcriptomic analysis of lipid synthesis metabolism in Camellia oleifera seed kernel during its maturation period. J Forest Environ. 2018;38(2):156-63.

54. Sellwood C, Slabas AR, Rawsthorne S. Effects of manipulating expression of acetyl-CoA carboxylase I in Brassica napus L. embryos. Biochem Soc Trans. 2000;28(6):598.

55. Pulsifer I, Kluge S, Rowland O. Arabidopsis LONG-CHAIN ACYL-COA SYNTHETASE 1 (LACS1), LACS2, and LACS3 facilitate fatty acid uptake in yeast. Plant Physiol Biochem. 2012;51:31-39. https://doi.org/10.1016/j.plaphy. 2011.10.003.

56. Sukumar V, Sastry P. Triacylglycerol synthesis in developing seeds of groundnut (Arachis hypogaea): acyl CoA synthetase and sn-glycerol3-phosphate acyltransferase in the maturing seed. Biochem Int. 1987:4:719-26.

57. Li Z, Tong M, Ling XP, Li J, Ning H. Overexpression of malonyl-CoA: Acp transacylase in Schizochytrium sp. to improve polyunsaturated fatty acids production. J Agric Food Chem. 2018;66(21):5382-91. https://doi.org/10. 1021/acs.jafc.8b01026.

58. Zhang HJ, Li ZL, Zhu HL. Advances in the research of $\beta$-ketoacyl-ACP synthase III (FabH) inhibitors. Curr Med Chem. 2012;19(8):1225-37.

59. Zhu L, Cheng J, Luo B, Feng S, Lin J, Wang S, Cronan JE, Wang H. Functions of the clostridium acetobutylicium FabF and FabZ proteins in unsaturated fatty acid biosynthesis. BMC Microbiol. 2009;9(1):119-119.

60. Bergler H, Fuchsbichler S, Högenauer G, Turnowsky F. The enoyl-[acylcarrier-protein] reductase (Fabl) of Escherichia coli, which catalyzes a key regulatory step in fatty acid biosynthesis, accepts $\mathrm{NADH}$ and 
NADPH as cofactors and is inhibited by palmitoyl-CoA. Eur J Biochem. 2010;242(3):689-94.

61. Liu H, Lu Q, Li H, Li S, Chen X, Liang X, Hong Y. Molecular mechanism of stearoyl-ACP desaturase gene FAB2 expression in peanut. Acta Agron Sin. 2019;45(11):1638-48.

62. Bhattacharjee A, Ghosh SK, Ghosh D, Ghosh S, Sen SK. Identification of a heat-stable palmitoyl/oleoyl specific acyl-acyl carrier protein thioesterase in developing seeds of Madhuca butyracea. Plant Science. 2002;163(4):791-800

63. Yingqi C. Lipid synthesis and beyond: SAD fatty acid desaturases contribute to seed development. Plant Cell. 2020;11:11.

64. Wang X. Principles and techniques of plant physiological biochemical experiment. Beijing: Higher Education Press; 2006.

65. Zhang F, Li Z, Tan X, Li W, Yang C, Li Y. Effects of BR application on the growth and physiological characteristics of Tung tree seedlings at different temperatures. Non-Wood Forest Res. 2018;036(003):17-24.

66. Popescu M, Avram MD, Oancea F, Lupu C, Cornea CP. Bioassisted azeotropic Soxhlet extraction of mustard oilseeds. J Biotechnol. 2017;256:S101.

67. GB5009.168-2016: national food safety standard: determination of fatty acids in food. In. China; 2016.

68. Greenspan P, Fowler MSD. Nile red: a selective fluorescent stain for intracellular lipid droplets. J Cell Biol. 1985;100(3):965-73.
69. Luo L, Xiao P, Du S, Jiang X, Guo X. Oil bodies observation and the correlation between the oil bodies and oil content in camellia oleifera seeds. J Chin Cereals Oils Assoc. 2014;29(11):82-5.

70. Zhang F, Lu K, Gu Y, Zhang L, Li Z. Effects of low-temperature stress and Brassinolide application on the photosynthesis and leaf structure of tung tree seedlings. Front Plant Sci. 2020;10:1767. https://doi.org/10.3389/fpls. 2019.01767.

71. Li B, Dewey CN. RSEM: accurate transcript quantification from RNASeq data with or without a reference genome. BMC Bioinformatics. 2011;12:323.

72. Robinson MD, McCarthy DJ, Smyth GK. edgeR: a bioconductor package for differential expression analysis of digital gene expression data. Bioinformatics. 2010;26(1):139-40.

73. Xie C, Mao X, Huang J, Ding Y, Wu J, Dong S, Kong L, Gao G, Li CY, Wei L. KOBAS 2.0: a web server for annotation and identification of enriched pathways and diseases. Nucleic Acids Res. 2011;39(Web Server issue):W316-322.

\section{Publisher's Note}

Springer Nature remains neutral with regard to jurisdictional claims in published maps and institutional affiliations.
Ready to submit your research? Choose BMC and benefit from:

- fast, convenient online submission

- thorough peer review by experienced researchers in your field

- rapid publication on acceptance

- support for research data, including large and complex data types

- gold Open Access which fosters wider collaboration and increased citations

- maximum visibility for your research: over $100 \mathrm{M}$ website views per year

At BMC, research is always in progress.

Learn more biomedcentral.com/submissions 